\title{
O Conjunto fotográfico no ensino de História: algumas possibilidades de abordagem com a imigração polonesa
}

\author{
The Joint Photographic History in teaching: \\ some possibilities to deal with immigration Polish
}

Jonathan Oliveira Molar *

RESUMO

O presente artigo pretende aproximar o campo This article aims to bring the field to the iconográfico ao ensino de História, isto é, iconographic history of education, so, explicitando possíveis caminhos para a explaining possible ways to use photography in utilização da fotografia em sala de aula, como the classroom, as methodological tool, ferramenta metodológica, demonstrando demonstrating the viability of the whole assim, a viabilidade do conjunto fotográfico no photographic aid in practice in this area of auxílio à prática docente na área, via a relação teaching through the teaching-learning ensino-aprendizagem. Ao longo de sua relationship. Throughout its history, trajetória, a fotografia foi marcada por seus photography has been marked by its uses and usos e funções, por sua grande capacidade de functions, for their great capacity for representação, abordá-la como indício do real representation, address it as evidence of the denota uma análise mais apurada e dinâmica real shows a more refined and dynamic in na pesquisa histórica. Inseri-la na prática historical research. Include them in teaching pedagógica significa explorar sua capacidade means exploring its representative capacity to representativa para o entendimento de uma understand one of the guiding lines of das linhas norteadoras dos Parâmetros Parâmetros Curriculares Nacionais (PCN's): Curriculares Nacionais (PCN's): a diversidade. diversity. In particular, this research, will De modo particular, nesta pesquisa, analisar- address the immigration issue to the se-á o tema imigração para a conjugação entre combination of education and photography, ensino e fotografia, visualizando as realidades viewing the social realities of a plural and sociais por um viés plural e particular.

PALAVRAS-CHAVE: conjunto fotográfico; repre- KEYWORDS: joint photographic; representasentação; ensino de História; imigração; iden- tion; teaching of history; immigration; identidade; Gazeta Polaca no Brasil; poloneses; tity; Gazeta Polaca no Brasil; poloneses; Brasil.

\section{Introdução}

O presente artigo tem por objetivo vincular a viabilidade das fontes fotográficas ao processo de ensino-aprendizagem na prática docente do ensino

\footnotetext{
* Bacharel em História; graduando em Direito e mestrando em Educação pela Universidade Estadual de Ponta Grossa (UEPG), bolsista da Coordenação de Aperfeiçoamento de Pessoal de Nível Superior (CAPES) / Brasil.
}

Antíteses, vol. 2, n. 3, jan.-jun. de 2009, pp. 269-296 http://www.uel.br/revistas/uel/index.php/antiteses 
de História. Ou seja, utilizá-la como método de análise interpretativo dos conteúdos proposto aos estudos em sala de aula e não por mera ilustração.

Nesse sentido, o prestígio e o fascínio exercido pelas imagens advêm de sua característica de representar o seu respectivo objeto, afinal, "substitui-se a experiência por representações” (JOLY, 1996). Sua função é evocar, via um processo de semelhança, sendo a imagem percebida como signo.

A imagem tem como princípio essencial sua heterogeneidade, expressado dessa forma por Joly:

[...] Isto é, (a imagem) reúne e coordena dentro de um quadro (ou limite) diferentes categorias de signos: 'imagens' no sentido teórico do termo [...] mas também signos plásticos (cores, formas, composição interna, textura) e a maior parte do tempo também signos lingüísticos (linguagem verbal). É sua relação, sua interação, que produz o sentido que aprendemos a decifrar mais ou menos conscientemente e que uma observação mais sistemática vai ajudar a compreender melhor (JOLY, 1996: 76).

Demonstra-se, pois, que a imagem é de fato uma linguagem específica e heterogênea, nessa qualidade, distingui-se do mundo "real" e, por meio de signos particulares, possibilita uma representação escolhida e orientada. Registrar os conhecimentos via a inserção do conjunto fotográfico, constitui-se como uma nova perspectiva paradigmática para a ação educativa, dessa forma, o processo de aprendizagem estará mais próximo das novas tecnologias de informação facilitando a prática docente.

Por seu dinamismo de situações, a fotografia, apresenta representações plurais, sui generis, da sociedade como um todo; pegar-se-á como exemplo, neste artigo, a imigração. Conteúdo esse, importante no âmbito do reconhecimento da pluralidade de culturas, ou seja, embasando-se o binômio grupos imigracionais e as sociedades "adotivas"; além da inserção nos currículos escolares do ensino de História das temáticas: imigração e a alteridade (carrochefe dos temas transversais, os quais são eixos articuladores do ensino como um todo).

Utiliza-se como fonte de análise e exemplificadora das possibilidades do conjunto fotográfico em sala de aula o periódico polonês Gazeta Polaca no Brasil (CURITIBA, 1937) -uma ferramenta identitária para os imigrantes poloneses que chegavam à América do Sul e deparavam-se com um novo mundo; a revista apresenta anúncios de comércios brasileiros, fotografias de colônias dos imigrantes, imagens sobre a Europa pré $2^{\text {a }}$ Guerra Mundial, etc. 
Recorta-se, no presente texto, as fotos das colônias de imigrantes, atrelando-as ao contexto brasileiro e polonês, além de imagens de países vizinhos ao Brasil e circundados pela bacia da Prata, como Argentina e Uruguai -averiguando assim, a abrangência do periódico e suas respectivas representações.

Para a melhor compreensão do periódico realiza-se a priori a contextualização da imigração polonesa para o Brasil e a discussão de duas noções fundamentais que perpassam a questão imigracional: cultura e identidade. A partir desses aportes chega-se a "Gazeta Polaca no Brasil" e suas potencializações enquanto ferramenta para o ensino de História.

\section{A fotografia como documento histórico.}

O mundo tornou-se de certa forma 'familiar' após o advendo da fotografia, tornou-se, assim, portátil e ilustrado (Kossoy, 2001: 26-27).

Muito há de se indagar sobre a relação entre a História e a fotografia, existindo dois possíveis caminhos para tal relação: o primeiro é tomar a direção de uma história da fotografia -os processos de evolução, a técnica, etc.; o segundo, buscar compreender o lugar da fotografia na História, em seu processo de conhecimento e apreensão das relações sociais. Nesse artigo, optase, primordialmente, pelo segundo viés.

Ao longo de sua trajetória, a fotografia foi marcada por seus usos e funções. Durante o século XIX sua difusão foi relacionada às formas de expressões artísticas, sendo relegado seu caráter questionador. Por sua grande capacidade de reproduzir o real, a fotografia foi envolvida por um clima "mágico"; tal concepção, que a vê como fidedigna do real suscitou polêmicas quanto a sua utilização como documento histórico e até que ponto era pertinente para a compreensão do todo social.

Em grande parte, pela colaboração da História Nova, o historiador voltou seu olhar para fontes pouco abordadas pela historiografia tradicional; alargouse assim, o campo de investigação e, consequentemente, de documento, para Jacques Le Goff: “(...) A História nova ampliou o campo do documento histórico (...) uma história baseada numa multiplicidade de documentos (...)" (LE GOFF, 1993: 28). Transformou-se, desse modo, os usos da fotografia no processo de pesquisa histórica. Segundo Ana Maria Mauad:

(...) entre o sujeito que olha e a imagem que elabora há muito mais que 
os olhos podem ver. A fotografia, para além de sua gênese automática, ultrapassando a idéia de analogon da realidade - é uma elaboração do vivido, o resultado de um ato de investimento de sentido, ou ainda uma leitura do real utilizada mediante o recurso a uma série de regras que envolvem, inclusive, o controle de um determinado saber de ordem técnica. (MAUAD, 1996, p. 75).

Entende-se, então, a fotografia como um indício interpretativo do real, por convenções e opções historicamente construídas. Ou seja, entre o objeto e a sua representação fotográfica interpõe-se uma série de opções que podem ser captadas dentro de um contexto mais amplo, tanto histórico quanto cultural. Neste sentido, comenta Boris Kossoy:

A fotografia ou um conjunto de fotografias não reconstituem os fatos passados...apenas congelam, nos limites do plano da imagem, fragmentos desconectantes de um instante...cabe ao intérprete compreender a imagem fotográfica enquanto informação descontínua da vida passada, na qual se pretende mergulhar (KOSSOY, 2001: 114115).

Nessa perspectiva, a imagem tornou-se transdisciplinar, segundo Mauad:

Tornava-se imprescindível que as antigas fronteiras e os limites tradicionais fossem superados. Exigiu-se do historiador que ele fosse também antropólogo, sociólogo, semiólogo e um excelente detetive, para aprender a relativizar, desvendar redes sociais, compreender linguagens, decodificar sistemas de signos e decifrar vestígios, sem perder, jamais, a visão do conjunto (MAUAD, 1996: 78).

A linguagem visual é o resultado de um jogo entre expressão e conteúdo, englobando uma tríade importante para sua decodificação: o autor, a imagem e o leitor. Desse modo, o destinatário, que recebe e analisa as imagens através do contexto histórico em que está envolvido e com base em seu capital cultural, elabora múltiplas interpretações sobre o conjunto iconográfico, que podem legitimar ou não as expectativas do autor que o produziu. A importância do leitor pode ser vista neste excerto de Kossoy: "O valor e o alcance dos documentos, bem como sua viável interpretação, estão na razão direta de quem consegue em função de sua bagagem cultural, sensibilidade, experiência humana e profissional -formular-lhes perguntas adequadas e inteligentes." (KOSSOY: 154).

A competência de quem olha imprime significados às imagens, não se limitando a uma compreensão uníssona, pelo contrário, leva a uma pluralidade de olhares. O conceito de habilidade do receptor depende de uma série de saberes que, para Mauad (1996), dá-se em dois níveis: interno -refere-se à superfície do texto visual, as estruturas espaciais; e o externo -a aproximação 
com outras fontes a respeito do tema trabalhado.

Vê-se, com isso, a importância de uma "leitura lateral" para o melhor aproveitamento da decodificação iconográfica em seu processo de conhecimento. Para Henrique M. Silva: “(...) a intercalação e o intercruzamento de fontes se tornam de fundamental importância na construção de um quadro de referências mais ampla para se compreender o sentido do conteúdo das imagens, a fim de que elas adquiram um sentido não em si, mas em seu contexto" (2000: 142).

Por meio da questão temporal, a imagem permite a "presentificação" do passado, pois, ao processar-se através do tempo, relaciona-se com o laço identitário, cabendo ao investigador averiguar as visões de mundo imbuídas na produção de uma determinada fotografia. Entende-se que numa dada sociedade existem, coexistem e se articulam múltiplos códigos e níveis de interpretação, fornecendo significados ao "universo" sócio-cultural, os quais são construídos na prática cotidiana. Segundo Mauad:

Toda imagem é histórica. O marco de sua produção e o momento de sua execução estão indefectivelmente decalcados nas superfícies da foto (...) a história embrenha as imagens, nas opções realizadas por quem escolhe, uma expressão e um conteúdo, compondo através de signos, de natureza não-verbal, objetos (...) significados de cultura. (MAUAD, 1996: 198).

Quando se utiliza o conjunto iconográfico para investigar a imigração, torna-se importante analisar como o grupo permite-se fotografar, e de que modo isto é realizado. Ou seja, sob qual perspectiva foi pensada determinada imagem?, Nessa ótica, explicita Silva: "Conhecer um pouco e previamente a história da comunidade ou grupo em estudo mostra-se imprescindível para viabilizar a utilização das fotografias durante a pesquisa (...)” (SILVA, 2000: 142).

\section{O ensino e as fontes fotográficas}

As novas tecnologias da comunicação e os meios de informação possibilitam distintas maneiras de codificar o mundo e seus interrelacionamentos. Enfatiza-se, pois, que a interface entre a linguagem visual e a educação como sendo condição essencial para promover uma nova forma de mediação pedagógica.

Contudo, tal tarefa não se compõe de uma atividade simples, 
principalmente, quando vinculada ao ensino, mais especificamente, ao processo de aprendizagem. Vê-se que, viver em um mundo desterritorializado e em constante período de transição, requer uma reavaliação tanto das bases fotográficas quanto educacionais (HALL, 1999).

O documento visual, a princípio, foi visto, graças a sua linguagem não escrita, como neutra, inquestionável, em outras palavras, um registro quase mecânico da realidade percebida, parecendo prescindir de análise de significados. Segundo Marcos Napolitano:

\begin{abstract}
Para o historiador, esses elementos da linguagem devem servir para a compreensão das estratégias dos diversos gêneros e tipos de televisão, para encenar, registrar, promover (...) Como a televisão talvez seja a mais poderosa experiência social das últimas décadas, encabeçando a mídia como um todo e muitas vezes dando-lhe a diretriz básica da abordagem do real, ela tem um poder enorme na própria fixação da memória social, selecionando eventos e personagens a serem lembrados ou esquecidos (NAPOLITANO, 2005: 279).
\end{abstract}

A fotografia, assim como, qualquer documento histórico, passa por filtros, recortes, manipulações. Desse modo, o critério de seleção do conteúdo e o que será repassado aos alunos depende, em grande medida, do professor, ou seja, a atuação do docente é mister para a elaboração bem sucedida do conjunto fotográfico no processo de ensino. Para Napolitano: "as fontes audiovisuais constituem um campo próprio e desafiador, que nos fazem redimensionar a permanente tensão entre evidência e representação (...)"(NAPOLITANO, 2005: 280).

Do ponto de vista educacional, por muito tempo, as fontes visuais foram condenadas, exploradas na periferia dos instrumentos utilizados em sala de aula. Para Vieira: “(...) seu caráter anti-educativo foi cantado em 'prosa e versos', por milhões de educadores nestas últimas décadas (...)” (VIEIRA, 2001, p. 5). Atualmente, pode-se perceber o esgotamento de um modelo educacional em que se trabalha, quase que exclusivamente, com as linguagens oral e escrita.

Os saberes escolares são produtos sociais e a organização de seu currículo interage diretamente na distribuição da sociedade, vê-se um modelo que gera desigualdades, eminentemente seletivo. Segundo Alice Ribeiro Casimiro Lopes:

(...) não podemos furtar a discutir o que é fundamental ser ensinado na escola. Não podemos negar o papel preponderante da escola como socializadora de saberes (...) Ao questionarmos a razão instrumental, os conhecimentos absolutizados, a unidade e a universalidade da razão, não devemos desmerecer a razão, a epistemologia, a relação dialética entre objetividade e subjetividade (LOPES, 1999: 166-167). 
Assim sendo, o sistema de ensino ao se desenvolver por "etapas", a longo prazo, torna-se fato existencial, afinal, refere-se ao modo como os homens adquirem sua essência real e, na maioria das vezes, conduzida. É também, fato social, sendo determinada pelos interesses que movem a comunidade a integrar ou afastar seus membros do modelo vigente; a educação é uma transmissão integrada da cultura, estimulando a consciência crítica. Conforme Jörn Rüsen:

\begin{abstract}
A consciência histórica representa, portanto, uma diferenciação e uma expansão da consciência do tempo (...) Como conteúdo da consciência histórica, história é a suma das mudanças temporais do homem e de seu mundo no passado, interpretadas como transformação de tempo (...) Com tal interpretação, ela se insere no quadro de referências de orientação da vida (RÜSEN, 2001: 78) .
\end{abstract}

Desse modo, deve-se enfocar o viés representativo das fotografias, pois, sendo um documento histórico é, obviamente, interpretado, manipulado, assim como, outras fontes historiográficas. A modificação deste processo é essencial para a efetivação da imagem em sala de aula, na relação dialética do ensino/aprendizagem.

\title{
Imagens e Representação
}

Para a análise das fotografias e propagandas imigracionais, torna-se importante, utilizar o conceito de representação como ferramenta metodológica. Principalmente, após a reviravolta quanto ao caráter mimético das imagens, ou seja, analisando-a partir de um processo interpretativo. Para Burke:

\footnotetext{
(...) a virada dos historiadores para a imagem ocorreu num momento de debate, quando pressuposições triviais sobre a relação entre 'realidade' e representações (...) foram desafiadas, um momento no qual o termo 'realidade' está cada vez mais sendo usado entre aspas. Nesse debate, os inovadores levantaram alguns pontos importantes em detrimento dos 'realistas' ou 'positivistas' (...) Eles apontaram para o 'ponto de vista' em fotografias e pinturas (...) referindo-se a ponto de vista físico e também ao que pode ser chamado 'ponto de vista mental' (...).

Imagens podem testemunhar o que não pode ser colocado em palavras. As próprias distorções encontradas (...) em representações são evidência de pontos de vista passados ou 'olhares' (...)" (BURKE, 2004, p. 37-38).
}

Com a Nova História Cultural (NHC), voltaram-se as atenções para questões relacionadas ao conceito de representação (BURKE, 2001) tais como: os princípios de inteligibilidade utilizados no plano social, à primazia atribuída a um tipo de divisão social que organiza e classifica as relações mentais, etc. 
(CHARTIER, 1990: 15). Entretanto, a definição de representação não se restringiu somente ao plano mental, das idéias, mas também, concentrou seu foco de análise no plano concreto das ações humanas. Para Sandra Jatahy Pesavento:

\begin{abstract}
Assumir essa postura implica admitir que a representação do mundo é, ela também, parte constituinte da realidade, podendo assumir uma força maior para a existência que o real concreto. A representação guia o mundo, através do efeito mágico da palavra e da imagem, que dão significado e pautam valores e condutas. Estaríamos, pois, imersos num 'mundo que parece', mais real, por vezes, que a própria realidade e que se constituem numa abordagem extremamente atual (PESAVENTO, 2002: 8).
\end{abstract}

No sistema de representações produzido por cada época, e no qual esta encontra sua unidade, o "verdadeiro" e o "ilusório" não estão isolados, mas ao contrário, unidos num todo, por meio de um complexo jogo dialético.

O plano social tende a caracterizar o campo das representações de forma reveladora, pois o caráter interdisciplinar e a diversidade de abordagens e tendências metodológicas acabam por se entrecruzar. Afinal, cada geração ou sociedade, carrega consigo uma definição particular de homem e de mundo e, a partir daí, um determinado imaginário.

Assim sendo, as épocas históricas têm suas "modalidades" específicas de imaginar, reagrupar e renovar suas representações sócio-culturais. Os imaginários constituem uma série de referências no vasto sistema simbólico, no qual a coletividade elabora e, posteriormente, produz seus objetivos. Conforme Chartier:

As representações do mundo social assim construídas, embora aspirem à universalidade de um diagnóstico fundado na razão, são sempre determinadas pelos interesses do grupo que as forjam. Daí para cada caso, o necessário relacionamento dos discursos proferidos com a posição de que os utiliza (CHARTIER, 1990: 17).

As percepções do plano social não atingem a ingênua pretensão tradicionalista da neutralidade, pois, produzem estratégias e práticas que tendem a imprimir uma autoridade institucionalizada; legitimando um projeto reformador ou justificando as escolhas e valores dos próprios indivíduos. Ou seja, as investigações sobre as representações estão calcadas no campo das “possibilidades”, cujos desafios se intercalam em termos de poder e legitimação.

Utilizando como meio os imaginários sociais é que um grupo designa a sua identidade, isto é, elabora certa representação de si. Estabelece-se, assim, a distribuição dos papéis e das posições na sociedade; constrói-se códigos e 
padrões de comportamento, cuja função é a fronteira existente entre o "nós" e o “eles”. Segundo Baczko:

(...) designar a identidade coletiva corresponde, do mesmo passo, a delimitar o seu território e as suas relações com o meio ambiente e, designadamente, com os outros; e corresponde ainda a formar as imagens dos inimigos e dos amigos, rivais e aliados, etc. O imaginário social elaborado e consolidado por uma coletividade é uma das respostas que esta dá aos seus conflitos, divisões e violências reais ou potenciais. Todas as coletividades têm os seus modos de funcionamento específicos a este tipo de representações. Nomeadamente, elaboram os meios da sua difusão e formam os seus guardiões e gestores (...) (BACZKO, 1985: 309).

O controle das representações - da sua reprodução, difusão e manejoassegura em graus variáveis uma real influência sobre os comportamentos e os relacionamentos humanos, resultantes de experiências e expectativas da coletividade. Para Baczko: “(...) insistimos no fato de os imaginários sociais não funcionarem isoladamente, entrando, sim, em relações diferenciadas e variáveis (...)” (Ibidem: 312). O imaginário atua sensivelmente na memória -onde os acontecimentos contam menos do que as representações que as dão origem e as envolvem- transformando-a num processo contínuo. Segundo Michael Pollak:

(...) podemos também dizer que há uma ligação (...) muito estreita entre a memória e o sentimento de identidade (...) é o sentido da imagem de si , para si e para os outros (...) a imagem que ela constrói e apresenta aos outros e a si própria para acreditar na sua própria representação, mas também para ser percebida de maneira como quer ser percebida pelos outros (...) Podemos portanto dizer que a memória é um elemento constituinte do sentimento de identidade, tanto individual como coletiva, na medida em que ela é também um fator extremamente importante do sentimento de continuidade e de coerência de uma pessoa ou de um grupo em sua reconstrução de si. (POLLAK, 1992:204).

Em síntese, o conceito de representação permite a um grupo legitimar sua imagem, inserido-lo no complexo tecido social, de forma a objetivar os conflitos e delimitar a figura que se quer repassar à sociedade.

\section{Imigração polonesa: contextualização}

Para a compreensão das imagens da Gazeta Polaca faz-se necessário contextualizar o processo imigracional polonês. Esse foi influenciado tanto por fatores ocorridos na Polônia quanto os da realidade brasileira, os quais contribuíram decisivamente para esse período.

No fim do século XVIII, a Polônia que era um dos maiores países europeus em séculos passados, passava, de modo geral, por sérias dificuldades, com isso, 
O Conjunto fotográfico no ensino de História: algumas possibilidades de abordagem...

seus países vizinhos -Rússia, Áustria e Prússia- aproveitaram a ocasião e repartiram-na entre si, por três ocasiões distintas (1772, 1793 e 1795).

Dessa forma, os poloneses perderam não só o seu poder político e econômico, mas também o controle de suas mais tradicionais expressões culturais. Segundo Rose dos Santos: "Os poloneses foram proibidos de falar seu idioma nos atos oficiais e nas escolas, impuseram-lhes a igreja ortodoxa (...) obrigaram também as vendas de terras agrícolas dos poloneses aos ocupantes" (SANTOS, 2005: 9). Em um sentido mais amplo, explica Neda Doustdar:

\section{(...) Em fins do século XVIII, a Polônia desapareceu como nação livre e independente, transformando-se num pedaço de chão da periferia oriental dos grandes centros de decisões localizados no ocidente da Europa. Frente a uma Europa que emergia da Revolução Industrial, a Polônia sofria os efeitos das forças medievais, principalmente de uma população camponesa feudalizada. Associada a isso, havia o domínio da ação conjunta de três potências ocupantes: a Áustria, a Prússia e a Rússia (DOUSTDAR, 1990: 76).}

Todo este conjunto de perdas criou um forte sentimento nacionalista, procurou-se neutralizar os valores estranhos à sua própria cultura, ameaçada desde a invasão "estrangeira" em seu território. Tais fatores contribuíram decisivamente para a imigração, motivando-os a encontrar nas Américas o que perderam em sua terra natal -a liberdade.

O Brasil durante o século XIX passava por uma série de transformações sociais. A partir de 1850 , com a lei $\mathrm{n}^{\circ}$ 601, conhecida como "Lei de Terras", a ocupação de terras devolutas passou a depender do título de compra, ou seja, institucionalizou-se a "propriedade privada da terra no Brasil" (CAPRI, 2003: 44). Desse modo, muito imigrantes se transformaram em "arrendatários", pois a posse das terras com tal medida pertencia ao Governo Provincial.

No mesmo ano de 1850, instituiu-se a "Lei Eusébio de Queirós", que proibia o comércio de escravos no contexto interprovincial. ${ }^{1}$ Em outros termos, com tal lei, percebia-se a iminente necessidade do braço do imigrante para as lavouras, afinal, o sistema escravista dependia de um constante e renovado "abastecimento" para que fosse levado à frente. Nesse contexto, expõe Iraci Salles:

A partir de 1850, através da efetiva extinção do tráfico negreiro e das pressões exercidas pela Inglaterra para o cumprimento de sua

\footnotetext{
1 Para o sistema industrial/capitalista, que já estava sendo gestado na Inglaterra desde o século XVIII, a busca por mão-de-obra barata e mercado consumidor tornava-se condição necessária para o desenvolvimento do sistema, assim, o tráfico negreiro, que fora utilizado em grande escala, passava a ser um empecilho.
} 
proibição, a classe dominante viu-se obrigada a buscar formas alternativas de utilização da força de trabalho que sustentasse a agricultura de exportação. Muito embora o contingente de escravos fosse significativo, sabia-se que tendia a decrescer, e a partir de 1856 , menção à falta de trabalhadores é constante tanto nos Relatórios de Presidente de Província, quanto nas discussões das Assembléias Legislativas. Tinha-se consciência do limite temporário da escravidão, e mesmo antes da cessação do tráfico já eram levantadas hipóteses sobre a possibilidade de se aprovar o trabalho livre, nacional ou estrangeiro (SALLES, 1986: 79).

O golpe final ao sistema escravista foi com a "Lei Áurea" (1888), já que a medida "Eusébio de Queiroz" não havia obtido a eficácia esperada, pois fora criado um mercado clandestino de compra e movimentação de escravos em "portos obscuros", deixou-se como alternativa última a abolição.

Dessa forma, os dirigentes políticos seguindo a política do "governar é povoar" (CAPRI, 2004: 45), com o objetivo de habitar os imensos territórios brasileiros despovoados, incentivaram os imigrantes a se estabelecerem em regime de pequenas propriedades, principalmente, no sul do Brasil -criaram-se, assim, colônias agrícolas para a produção de gêneros de primeira ordem; outros imigrantes fixaram-se nas cidades, trabalhando em empregos modestos, "dessa forma, transformaram o perfil urbano e rural da população brasileira" (SALLES, 1989: 93).

Segundo a visão da elite agrária, o imigrante europeu seria a antítese do negro, tido como: preguiçoso, indolente, etc.; esperava-se que o trabalhador estrangeiro reabilitasse $\mathrm{o}$ ato de laborar e imprimisse uma característica civilizadora à sociedade brasileira. Este imigrante era visto como: "O imigrante laborioso, inteligente, vigoroso e que aspira à fortuna é o desejado pelos proprietários paulistas, como o trabalhador que completa o quadro da sociedade que aspiram construir" (Ibidem).

Além de todas essas questões que motivaram diretamente a imigração, o Brasil passava em fins do século XIX e início do XX -com a crise do Império e a instauração da República- por uma onda científico-tecnológica, e pela crença positivista na infalibilidade do progresso. Influenciados pela $2^{\circ}$ Revolução Industrial, ${ }^{2}$ pretendia-se a aceleração da industrialização, a urbanização, o branqueamento populacional, entre outras medidas europeizantes. Segundo Sevcenko:

2 Denominação tradicionalmente atribuída à Revolução Industrial a partir de 1860, quando esta, expandiu-se das fronteiras inglesas para outras nações. 
(...) Um tempo [o do advento republicano] mais acelerado, impulsionado por novos potenciais energéticos e tecnológicos, em que a exigência de acertar os ponteiros brasileiros com o relógio global suscitou a hegemonia de discursos técnicos, confiantes em representar a vitória inelutável do progresso e por isso disposto a fazer valer a modernização 'a qualquer custo'. As ações concretas desencadeadas por esses discursos...se traduziram em formas extremas de opressão quando voltadas para as populações destituídas de qualquer educação formal e alheadas dos processos decisórios (SEVCENKO, 1998: 27).

Em resumo, o panorama das transformações da realidade brasileira contribuiu para o processo imigracional, além da iniciativa oficial do Estado de apoio à imigração, como por exemplo: facilidades na aquisição de propriedades agrícolas, auxílio na distribuição, compra de instrumentos e insumos agrícolas, transporte marítimo gratuito, etc. (Stawinski, 1976).

Segundo Rose dos Santos, os primeiros poloneses que chegaram ao Brasil vieram da Silésia (região sul da Polônia) cujo domínio estava nas mãos do Império Prussiano. Fixaram-se em Brusque (Santa Catarina), em 1869, constituídos por dezesseis famílias. Uma proposta de sistematização da imigração polonesa aponta três etapas: 1860-188o, etapa preliminar; 1880-1918, emigração econômica de massas; 1918-1939, período do entre-guerras. O Brasil foi um destino importante desses fluxos, principalmente na etapa intermediária, cuja denominação fora a de "febre migracional" (DECOL, 2000: 2).

\section{Cultura e identidade: interpretações plurais}

Vinda do latim, cultura significava o cuidado dispensado ao campo. A partir do século XVI, seu sentido foi se transformando, passando a designar uma "faculdade", ou seja, algo que deve ser desenvolvido. De fato, a conotação figurada do conceito de cultura deu-se apenas no século XVIII, com o Dicionário da Academia Francesa. Citava-se, então, a cultura "das artes", “das letras”, etc. Nesse mesmo século surgiu a idéia de civilização, que vinha se juntar à noção de cultura. Estas pertenciam ao mesmo campo semântico, porém sofreram designações divergentes, paradoxais. Em um primeiro momento, cultura designava o progresso individual e civilização o progresso coletivo; contudo, com a exacerbada rivalidade entre França e Alemanha, estas denominações receberam outras conotações de cunho ideológico (ELIAS, 1993).

Na Alemanha, o mito do Estado-Nação foi evocado pelo significado de cultura, o fator aglutinador de um povo, que até então permanecia sem qualquer 
unidade -tanto cultural quanto política. Evocava-se, assim, "o gênio nacional" (Volksgeist) identitário. Já na França, o termo adotado fora civilização, influência do pensamento iluminista -universalizante, racional- pois designava a coletividade, com destaque para a unidade nacional francesa, conquistada séculos atrás. Ao longo de gerações a rivalidade franco-alemã persistiu, decorrendo disso, discursos discriminatórios e confrontos.

A cultura voltaria às discussões historiográficas, com maior ênfase, nos anos 1960, com a Nova História -desdobramento da Escola de Annales- e a Nova Esquerda Inglesa. Assimilava-se, desde então, uma disposição para a pesquisa com novas fontes e a re-elaboração de alguns conceitos (LE GOFF, 1993), dentre esses, o de cultura. Por conseqüência, durante a década de 80, com a NHC, acentuou-se o entrecruzar da História com a Antropologia e outras disciplinas "irmãs" etc. Segundo Burke: "O novo estilo da história cultural deve ser visto como uma resposta aos desafios descritos, à expansão do domínio da 'cultura' e à ascensão do que passou a ser reconhecido como 'teoria cultural' (...)" (BURKE, 2001: 69).

A noção relativizante, adotada para a concepção de cultura, dinamizou a forma de concebê-la, permitindo seu enriquecimento, retirando, em grande parte, o reducionismo e as ambigüidades que lhe foram atribuídas em suas primeiras conceitualizações. Desmontando-se, assim, as explicações naturalizantes e definidas à priori, que pautavam a abordagem sociológica de uma história social da cultura. Para Roger Chartier:

\begin{abstract}
O procedimento supõe uma tomada de distância em relação aos princípios que fundavam a história social da cultura na sua acepção clássica. Um primeiro distanciamento estabeleceu-se face a uma concepção estritamente sociográfica que postula que as clivagens culturais estão forçosamente organizadas segundo um recorte social previamente construído. É preciso, creio, recusar esta dependência que refere as diferenças de hábitos culturais a oposições sociais dada a priori, tanto à escala de contrastes macroscópicos (...) quanto à escala das diferenciações menores (CHARTIER, 1991: 180).
\end{abstract}

Após o repensar dessas teorias naturalizantes, abriu-se espaço para abordagens mais flexíveis e condizentes para com o espaço cultural contemporâneo, afinal, viu-se, os comportamentos humanos pelo prisma do relativismo e interpretados pela carga cultural em intensas relações de "troca".

O conceito de cultura conserva-se não como um todo explicativo e terminal dos inter-relacionamentos humanos, mas de modo a tecer as complexas malhas cotidianas, através do fluxo dos comportamentos (ação social) em que as formas 
culturais encontram articulação. Segundo Clifford Geertz "o homem é um animal amarrado a teias de significados que ele mesmo teceu (...)” (1974: 4).

A cultura não é um poder, algo no qual podem ser atribuídos casualmente os acontecimentos sociais, os comportamentos etc.; a cultura envolve o contexto social que permeia, ao mesmo tempo, em que se vê envolvida por este. Conforme Cuche:

Cada cultura é dotada de um 'estilo' particular que se exprime através da língua, das crenças, dos costumes, também da arte, mas não apenas desta maneira. Este estilo, este 'espírito' próprio a cada cultura influi sobre o comportamento dos indivíduos (CUCHE, 1999: 45).

Desse modo, a cultura e, mais especificamente, a variabilidade cultural torna-se visível, deixa de ser um capricho ou um vício historiográfico, para, ao contrário, apresentar-se de modo relevante para a compreensão de relações híbridas. Guiando, desse modo, os padrões culturais -sistemas criados historicamente, em termos dos quais os homens dão forma, ordem e direção (Geertz, 1974).

Deve-se, contudo, "relativizar o relativismo cultural", pois extremar tal conceito pode se tornar prejudicial à pesquisa, mas é inegável o caráter de "fluidez" que a relatividade aplica às relações sociais. Recorrer ao relativismo para compreender o grupo imigracional significa dar-lhe um caráter sui generis, entender sua especificidade, mas também os seus possíveis vínculos culturais mais amplos. Segundo Chartier:

Enfim, ao renunciar ao primado tirânico do recorte social para dar conta dos desvios culturais, a História em seus últimos desenvolvimentos mostrou, de vez. (...) que sua distribuição e seus usos numa dada sociedade não a organizam necessariamente segundo divisões prévias, identificadas a partir de diferenças de estado e de fortuna. Donde as novas perspectivas abertas para pensar outros modos de articulação entre as obras ou as práticas e o mundo social, sensíveis ao mesmo tempo à pluralidade de clivagens que atravessam uma sociedade e à diversidade dos empregos de materiais ou de códigos partilhados (CHARTIER, 1991: 177).

De forma particular e agregado à cultura, o conceito de identidade permite que um indivíduo se localize em um sistema social e seja localizado por este; e, mais amplamente, realiza a identificação de uma comunidade. A construção da identidade se faz no interior de contextos sociais que determinam as posições dos grupos e, conseqüentemente, orientam suas representações e práticas culturais.

A noção de identidade há muito vem se modificando. Para os iluministas 
esta se baseava no ideal da pessoa humana como um indivíduo totalmente centrado e unificado, ou seja, sua razão e consciência emergiam ao nascer sendo essencialmente as mesmas durante sua vida. Atualmente, têm-se o que Stuart Hall (1999) chama de a "crise da identidade", sendo entendida como um processo amplificado de modificações, onde as estruturas e processos centrais são deslocados nas sociedades modernas; abalam-se, com isso, os quadros identitários que fornecem uma referência estável aos indivíduos no mundo social.

Sendo a identidade uma construção social, do âmbito das representações e não um dado pronto e acabado, isso não significa que ela fique fundamentada apenas no plano das "idéias", dependendo exclusivamente da subjetividade do pesquisador ou dos agentes sociais. A construção da identidade produz efeitos sociais reais, os quais interferem nos relacionamentos humanos.

Fredrick Barth parte do pressuposto de que a idéia de etnicidade/identidade não define uma sociedade em sua totalidade e, menos ainda, uma cultura; embora haja grupos que compartilhem uma mesma cultura, suas diferenças não conduzem à formação ou reconhecimento de comunidades distintas. O que se torna diferencial para Barth é:

\begin{abstract}
As características que são levadas em consideração não são a soma das diferenças 'objetivas', mas somente aqueles que os próprios atores consideram significantes (...) alguns traços culturais são utilizados pelos atores como sinais e emblemas de diferenças, outros são ignorados e , em alguns relacionamentos, diferenças radicais minimizadas e negadas. O conteúdo cultural das dicotomias étnicas parece ser analiticamente de duas ordens: 1. sinais ou signos manifestos - os traços diacríticos que as pessoas procuram e exibem para demonstrar sua identidade (...) e 2. orientações de valores fundamentais, os padrões de moralidade e excelência pelos quais as ações são julgadas (BARTH, 1998: 194).
\end{abstract}

Ou seja, torna-se essencial, não inventariar seus traços culturais distintos, mas os que são utilizados pelos atores sociais como fator de afirmação e mantenedor de suas diferenças culturais. A formação ou desagregamento das identidades resultantes das interações entre os grupos são praticáveis em movimentos de construção e reconstrução contínua. Segundo Stuart Hall:

(...) a medida em que os sistemas de significação e representação cultural se multiplicam, somos confrontados por uma multiplicidade desconcertante e cambiante de identidades possíveis, com cada uma das quais poderíamos nos identificar - ao menos temporariamente (HALL, 1999, p. 13).

Uma determinada coletividade pode funcionar admitindo em seu meio uma pluralidade cultural e, ainda assim, manter a fronteira étnica. As fronteiras 
não são imutáveis e estáveis, mas suscetíveis a renovações. Segundo Barth:

\begin{abstract}
(...) a fronteira étnica canaliza a vida social -ela acarreta de um modo freqüente uma organização muito complexa das relações sociais e comportamentais. A identificação de outra pessoa como pertencente a um grupo étnico implica compartilhamentos de critérios de avaliação e julgamento. Logo, isso leva à aceitação de que os dois estão fundamentalmente jogando o mesmo jogo' (...) De outro modo, uma dicotomização dos outros como estrangeiros, como membros de outro grupo étnico, implica que se reconheçam limitações na compreensão comum, diferenças de critérios de julgamento, de valor e de ação, e uma restrição da interação em setores da compreensão comum assumida e de interesse mútuo (BARTH, 1998: 196).
\end{abstract}

A antiga unificação do conceito de "identidade" passa a se fragmentar, compondo-se de múltiplas identidades, algumas vezes contraditórias e nãoresolvidas. O próprio processo de identificação através do qual se projetam as identidades culturais tornou-se provisório e instável.

\title{
O periódico “Gazeta Polaca no Brasil”: fotografia e ensino de História
}

Inserido nas propostas preconizadas pelos Parâmetros Curriculares Nacionais (PCN's), nos $2^{\circ}$ e $3^{\circ}$ ciclos, têm-se o tema imigração enquanto meio para que se compreenda a noção de diversidade, de convivência com a diferença, com o "outro"; segundo o citado documento: "Reconhecer algumas relações sociais, econômicas, políticas e culturais que sua coletividade estabelece ou estabeleceu com outras localidades, no presente ou passado" (BRASIL, 1997: 47). Assim, pode-se introduzir nesta discussão a potencialidade da fotografia no processo de ensino por um viés prático: os imigrantes.

Considerando tal aspecto, pode-se analisar algumas fotografias sobre a imigração polonesa, ambas encontradas em um periódico voltado para estes grupo imigracional, a Gazeta Polaca no Brasil (CURITIBA, 1937). Utilizá-las como fonte primordial significa representar de que modo o conjunto fotográfico pode embasar historicamente os alunos, ajudando-os a compreender o sentido de diversidade, identidade, etc.

O periódico representa a expressão das tradições culturais e identitárias dos poloneses, sendo um elemento aglutinador para os que emigraram. Pretende-se, pois analisar de que forma a Gazeta Polaca elabora a representação destas características, de forma a se obter uma interpretação aprofundada via imagens.

No periódico, encontram-se fotos de colônias polonesas, principalmente, 
retratando clubes -locais de integração e comunicação entre os imigrantes. Fator comum destas fotografias são as poses aprumadas e alinhadas, típicas das primeiras décadas do século XX. Segundo Sant'anna:

(...) em relação à imagem fotográfica, por exemplo, sabemos que os primeiros aparelhos fotográficos possuíam uma baixa sensibilidade à exposição da luz, o que exigia uma imobilidade corporal do sujeito fotografado (...) Fator este que, em certa medida, contribuiu para dar às imagens do passado um ar grave e uma aparência hierática (...) (SANT'ANNA, 1981:90).

FIGURA 1 - Inauguração de um clube polonês em Guarapuava -PR.

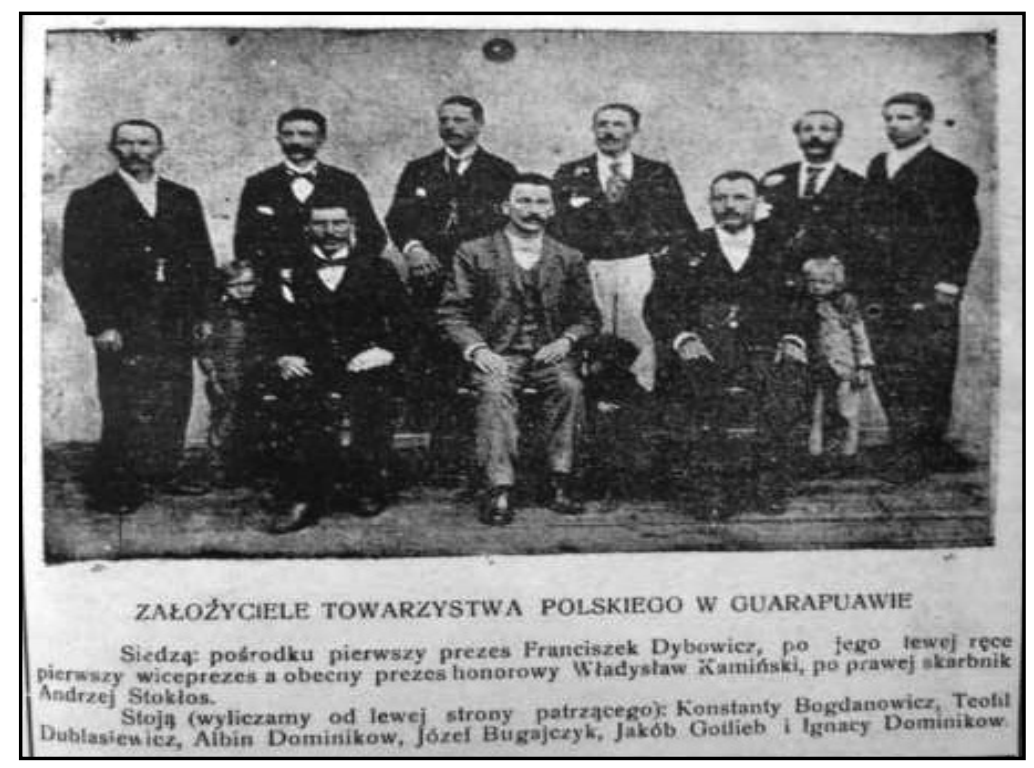

Fonte: Gazeta Polaca, 1937: 113.

A fotografia acima indica a instalação do clube polonês em Guarapuava, estado do Paraná, constando na imagem duas crianças e a diretoria da instituição. Em pose estática, fator já explicitado por Sant'anna, pode-se notar também a vestimenta alinhada dos senhores -“acontecimentos" importantes mereciam todo cuidado, afinal, esta imagem entraria para a posteridade do clube polonês. Quanto à disposição destes senhores na imagem, há o respeito à hierarquia, no centro está o fundador e seus colaboradores mais próximos; nos flancos da fotografia, outros membros da diretoria, os quais, provavelmente, ocupavam cargos de menor "responsabilidade" (considerações feitas com o auxílio da legenda, cujos cargos estão descritos).

As duas crianças da fotografia representam o futuro -não só do clube, mas, da comunidade polonesa- atribuindo, tradicionalmente, aos pequenos, adjetivos como: pureza, novas perspectivas, entre outros. Utiliza-se assim, o 
artifício de inserir crianças em representações de famílias ou grupos, principalmente, em momentos de realce da nacionalidade, não só dos colonos poloneses, mas de comunidades em geral.

A fotografia, em linhas gerais, significava uma ferramenta agregadora para os imigrantes, afinal estreita-se um vínculo com a memória. Esta deve ser entendida, sobretudo, como um fenômeno coletivo e social, sendo construído em seu cotidiano e submetido a transformações, re-ordenações. Para Pollak:

\section{Manter a coesão interna e defender as fronteiras daquilo que um grupo tem em comum, em que se inclui o território [no caso de Estados], eis as duas funções essenciais da memória comum. Isso significa fornecer um quadro de referências e de pontos de referência (POLLAK, 1989: 9).}

Em uma das propagandas observadas no periódico, acha-se o atelier fotográfico "Progresso", de August Weiss. Nela, explicita-se no discurso a sua versatilidade -retratos individuais, em grupos, fotos para passaportes, documentos, etc. Vale ressaltar o nome dado ao estabelecimento(-), "Progresso", termo que remete à crença positivista de modernização e desenvolvimento.

FIGURA 2 - Propaganda do atelier fotográfico "Progresso".

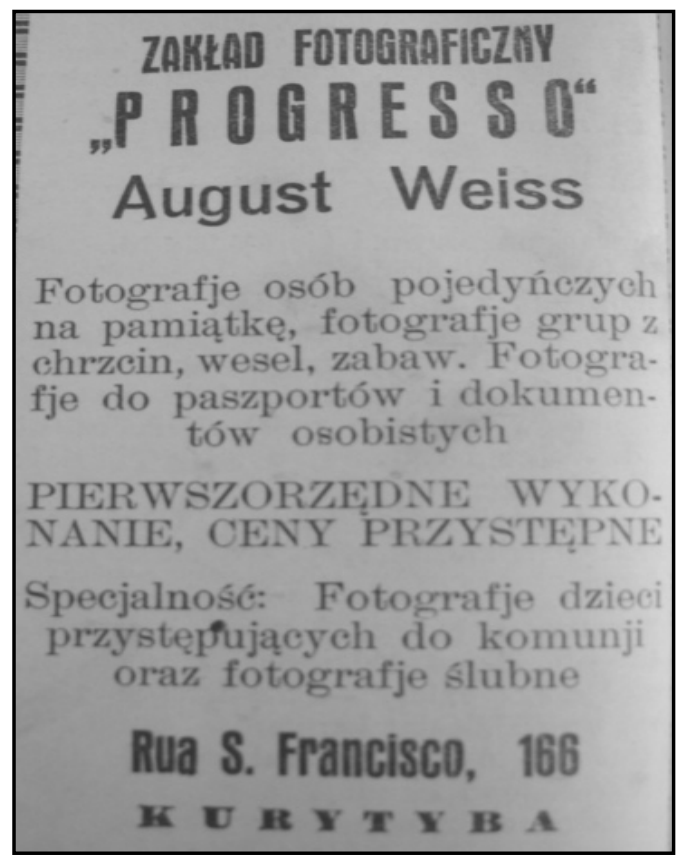

Nota: Gazeta Polaca, 1937: 64.

O que levaria um comércio brasileiro ou pertencente a outros grupos imigracionais a anunciarem seus estabelecimentos em um periódico voltado 
para poloneses? Duas possibilidades podem ser levantadas e atreladas: a primeira deve-se à procura por fotografias pelos poloneses, tornando-se assim um negócio lucrativo para a casa "Progresso"; a segunda, pela abrangência de veiculação do periódico. Ou seja, os dois apontamentos estão vinculados perfazendo um conjunto rentável para os anunciantes da revista, neste caso, o ramo fotográfico.

Na próxima imagem caracteriza-se o clube e escola polonesa em Guarani, estado de Santa Catarina. Nessa figura, nota-se a presença de diversas faixas etárias, além de um elemento importante: duas bandeiras hasteadas, provavelmente as do Brasil e da Polônia. Ou seja, o elo identitário entre os imigrantes poloneses para com seu país adotivo.

Essa fotografia tem em sua composição espacial uma peculiaridade: há uma variedade de disposições de seus "personagens" -homens, mulheres e crianças em alguns momentos aparecem em um mesmo espaço da fotografia, principalmente no centro da imagem e a esquerda (comumente os retratos de grupos apresentam uma divisão hierárquica - crianças e mulheres nos extremos e homens ao centro).

Por conseguinte, pode-se argumentar que fora uma estratégia (do fotógrafo, ou do próprio grupo) para exprimir coesão, já bastante referida e que perpassa a grande maioria do conjunto iconográfico da Gazeta Polaca.

FIGURA 3 - Inauguração do clube e escola polonesa em Guarani - SC.

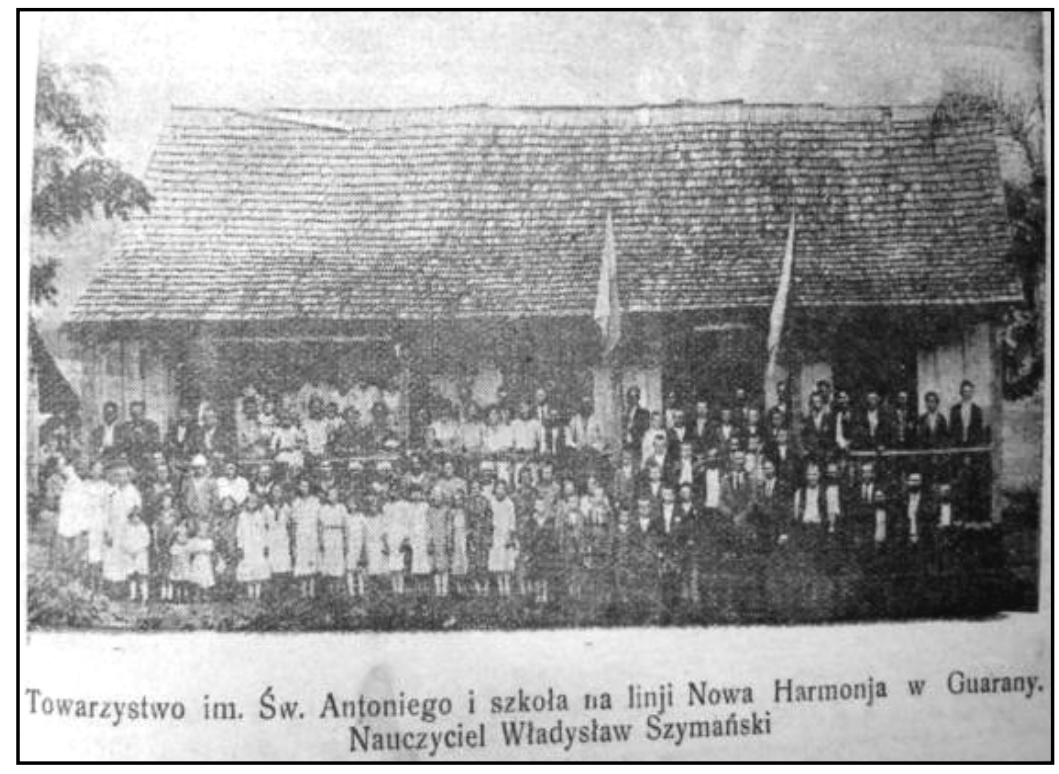

Nota: Gazeta Polaca, 1937: 109. 
Na imagem seguinte, retrata-se um outro clube polonês em Guarapuava PR, o interessante a ser analisado é o fundador do clube, o político Francisco Missini, o qual encontra-se no centro da fotografia. Da pequena parte de poloneses que não eram camponeses, este é um exemplo do sucesso de alguns indivíduos em atividades urbanas (DEMBICZ, 1998) ou, nesse caso, de um imigrante ocupando um cargo público.

Desse modo, particularmente, os poloneses, destacaram-se principalmente nas seguintes áreas profissionais: professores, religiosos, escritores e médicos, recebendo de uma parcela da população brasileira, em alguns momentos, respeito e credibilidade. (Ibidem.)

FIGURA 4 - Clube polonês em Guarapuava - PR.

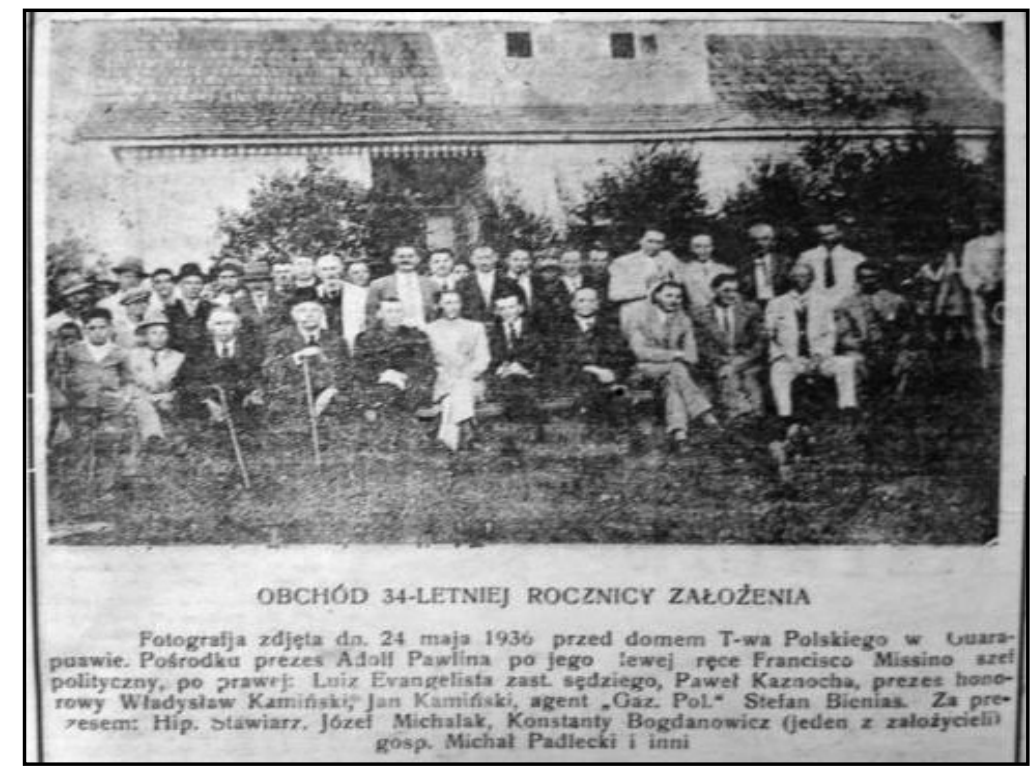

Nota: Gazeta Polaca, 1937: 114.

As fotografias são um indicativo de que, seja em família, no grupo ou na comunidade, tornava-se importante expressar o sentimento de união e de prosperidade dos imigrantes. Considerando-se que ao emigrarem e aportarem em países desconhecidos, estes se deparavam com novos desafios em seu cotidiano, os quais atuavam no imaginário dos imigrantes, como demonstra o colono Antônio Zielinski: “(...) Disseram que havia animais ferozes. Mas, nós ainda não vimos nenhum (...) Disseram que não havia igrejas (...) o idioma daqui é diferente do nosso e se parece com a vozearia dos gansos (...)" (STAWINSKI, 1976: 194). Naturalmente, era importante representar-se de 
forma positiva nas imagens, enfatizando que as dificuldades não retardaram a prosperidade da comunidade polonesa.

A revista explicita na apresentação que sua veiculação abrange o Brasil e a América Platina, sendo as fotografias um indicativo dessa realidade, como a do Bosque de Palermo, em Buenos Aires. ${ }^{3}$ Desse modo, porque o periódico teria uma circulação tão ampla?

FIGURA 5 - Parque Palermo em Buenos Aires - ARG.

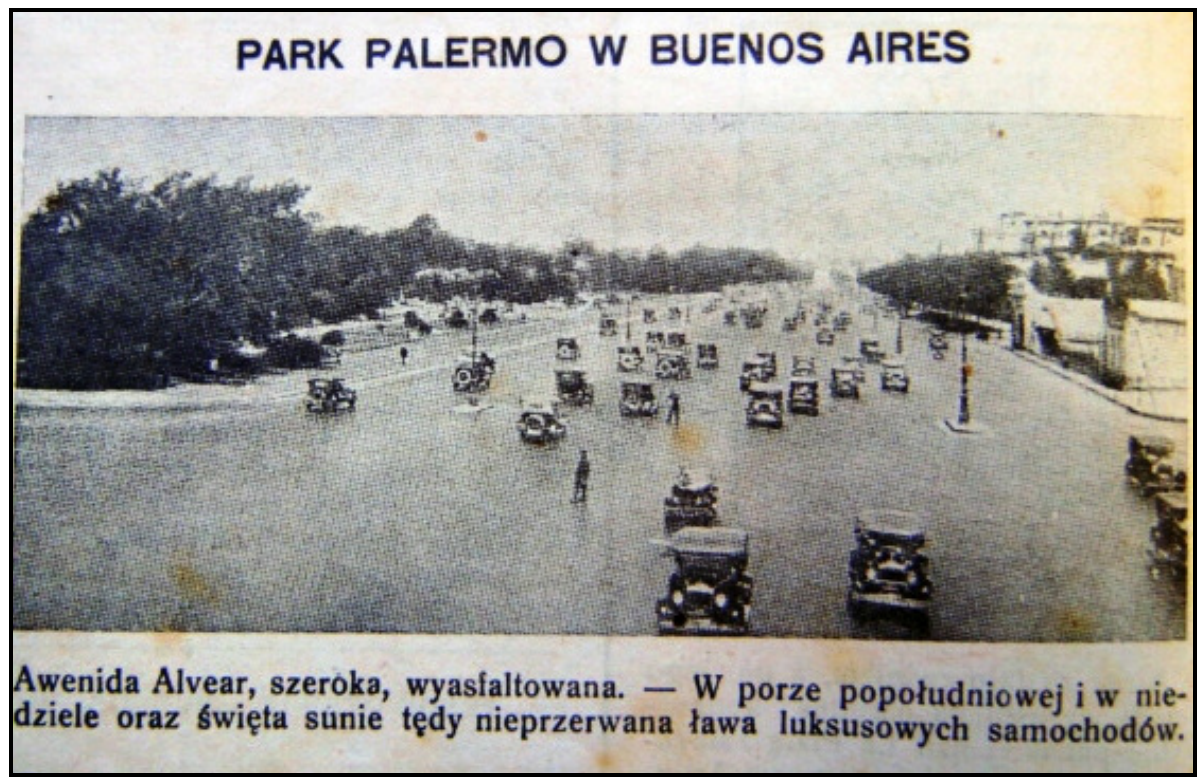

Nota: Gazeta Polaca, 1937: 60.

Representando-se na revista diversas localidades do Brasil e de seus países vizinhos, subentende-se, dessa forma, que havia leitores nesses países que se identificavam com o periódico; ou seja, a revista ao explicitar lugares plurais pretendia demonstrar aos poloneses que mesmo em territórios distantes, estes estavam unidos pelo sentimento de polonidade, além, é claro, de enfatizar a abrangência da imigração polonesa na América.

Encontra-se também no periódico, um curioso mapa que contém informações históricas sobre as expedições na bacia do Prata de Alvar Nunez, "o Cabeça de Vaca", descobridor das cataratas do Iguaçu e, posteriormente, governador do vice-reino de Assunção.

3 Designado como "um lugar muito bonito, durante um domingo santo", vê-se a grande circulação de carros e em menor número de pedestres, em uma movimentada avenida de Buenos Aires. 


\section{FIGURA 6 - Mapa geográfico e histórico da Bacia do Prata.}

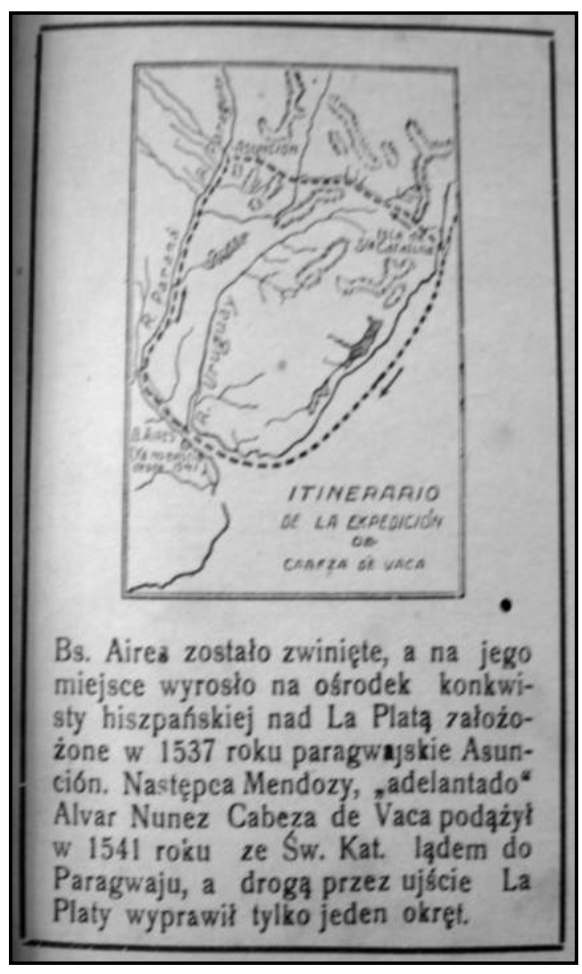

Nota: Gazeta Polaca, 1937: 59.

Dessa forma, percebe-se que a revista não só apresenta lugares desconhecidos por alguns imigrantes, acentuando o sentimento de polonidade, mas, também, faz questão de embasá-los historicamente. Assim sendo, muito mais que um meio de informação, a Gazeta Polaca pretendia auxiliar o imigrante de forma ampla.

O fato de emigrarem para novas regiões, tornava suas informações importantes. Assim, atenta-se que essa contextualização podia representar ao imigrante um alento e segurança para o reconhecimento de sua "nova" vida e de áreas vizinhas.

O sentimento de identidade está constantemente presente na revista, como no caso de imagens de lugares na Polônia. Por exemplo, o ginásio Rainha, localizado na praça das três cruzes em Varsóvia, adjetivado de "belo e muito conhecido"; ou então, o Jordanowskiego, um parque também da capital polonesa, para as crianças brincarem. 
O Conjunto fotográfico no ensino de História: algumas possibilidades de abordagem...

\section{FIGURA 7 - Praça das treze cruzes em Varsóvia - POL.}

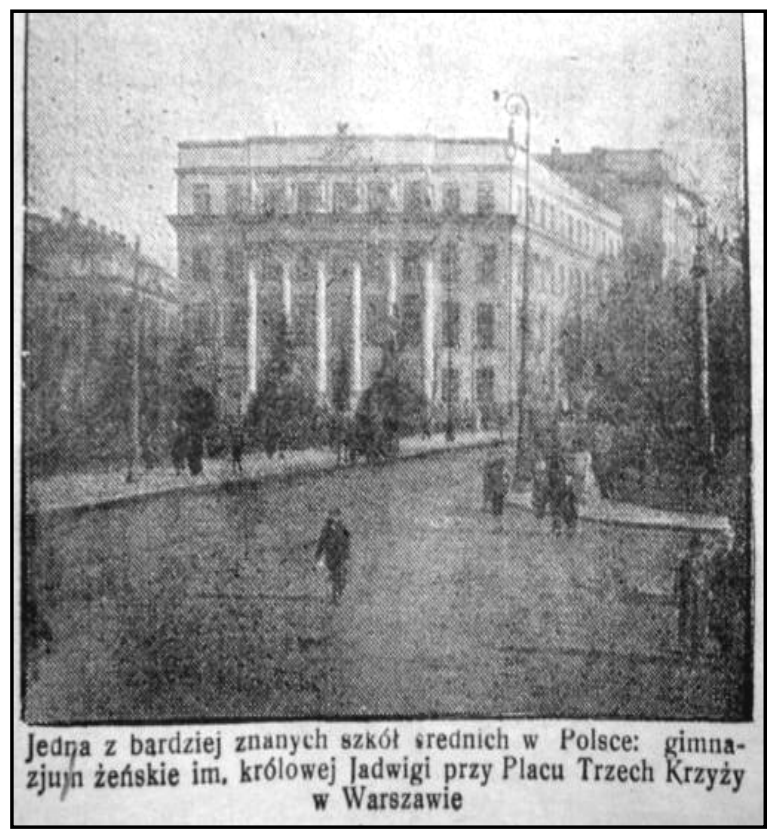

Nota: Gazeta Polaca, 1937: 54 .

\section{FIGURA 8 - "Belo" jardim de Varsóvia - POL.}

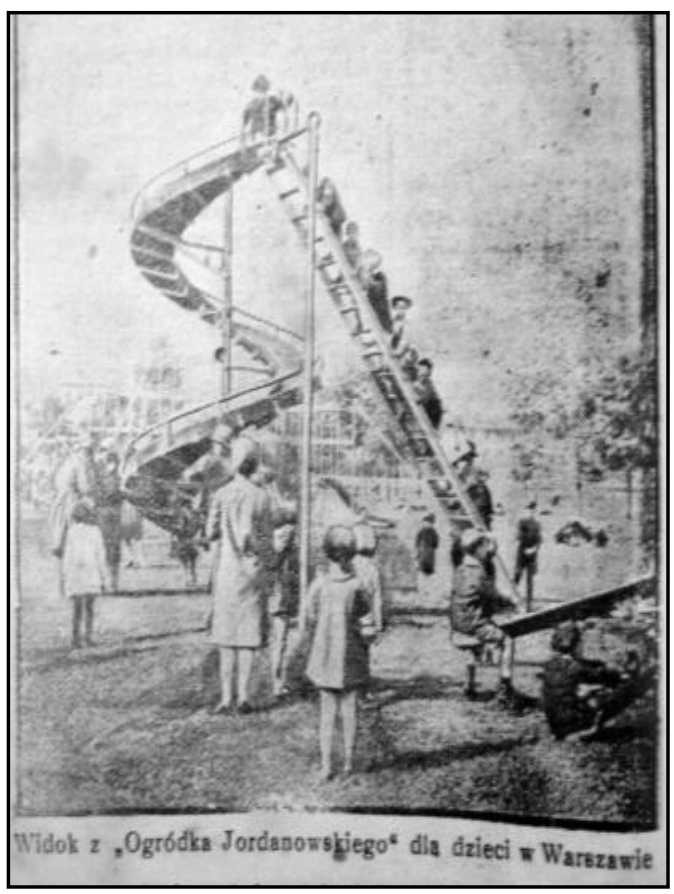

Nota: Gazeta Polaca, 1937: 52.

A interação entre as imagens e notícias tanto da Polônia quanto dos países que receberam os emigrantes esboça-se uma tentativa de dar representatividade ao grupo polonês. O sentimento de identidade deveria ser mantido com base no 
reconhecimento de lugares de Varsóvia, um atenuante para a nostalgia da terra natal, além de visualizar em seus novos destinos, futuros referenciais identitários.

Desse modo, pelo sistema de ancoragem proposto por Barthes (1971), imagens e palavras interagem com o objetivo de vincular América Platina/Brasil/Polônia, tanto geograficamente quanto historicamente. Afinal, os poloneses que desembarcavam na América do Sul não conheciam os lugares, símbolos, etc., ao passo que, seus descendentes já naturais de seus países de adoção -pois o periódico é de 1937- não chegaram a conhecer a Polônia.

Assim sendo, o periódico realizava a função de elo desta via de mão dupla, embasando os imigrantes de forma ampla, seja por informações sobre o cotidiano ou por fatos históricos, auxiliando-os sócio/culturalmente.

De fato, explanar as fotografias em sala de aula consiste no enveredar de reconhecimentos e surpresas, tal relação, torna-se dialética a partir do momento em que é visualizada como constituinte de um mesmo entorno -uma ferramenta para análise de um período da história do Brasil- o qual trouxe uma miscelânea de culturas, etnias, etc. Desse modo, contribuindo decisivamente para o reconhecimento de um Brasil plural, devendo, pois, ser abarcada pela prática de ensino, mais especificamente, na relação ensino-aprendizagem.

O conjunto iconográfico fornece aos educandos um panorama amplo que abarca desde a contextualização do período até a forma com as poses nas fotografias eram constituídas (ou seja, a técnica e a representação). Assim, considera-se a imagem enquanto elemento importante na formação de conhecimentos, agregando, nesse caso, imigração e alteridade.

Conforme explicita a revista Nova Escola, sobre os PCN's, ressalta-se a necessidade de promover e estimular nos alunos a consciência da sociedade em que se vive, inseri-se aí, a noção de diversidade. Procura-se estabelecer as relações entre identidades individuais, sociais e coletivas, relacionar o particular com o geral. Segundo o periódico:

\begin{abstract}
Ao propor o estudo da História local, o professor estará fazendo com que o aluno amplie sua capacidade de observação do mundo que o rodeia e diversifique suas relações. $\mathrm{O}$ estudante terá mais facilidade em compreender a História se começar a abordá-la pelo tempo presente. Ele pode ver o mundo de hoje e diferenciá-lo de outros tempos por meio de objetos antigos que são o testemunho de outras formas de vida [...] (Nova Escola, 2003: 44).
\end{abstract}

Assim, os PCN's ressaltam o compreender de relações contraditórias, 
variadas, pregando que o caminho para o discernimento dos alunos deve passar pelo estudo destas situações, tendo por fonte diversificados caminhos. Contudo, visualiza-se uma preocupação abundante sobre a não fidedignidade do conjunto fotográfico, pode-se dizer até, que demasiadamente atenta-se para essa questão o que não ocorre ao citar outros documentos abordados em sala de aula. $\mathrm{Ou}$ seja, ressaltam-se mais os perigos aos benefícios das fotografias no ensino, segundo os PCN's:

Os documentos são fundamentais como fontes de informações a serem interpretadas[...] nesse sentido, eles não contam, simplesmente, como aconteceu a vida no passado [...] visões de mundo de indivíduos ou grupos sociais. São interpretadas, então, como exemplos [...] de visões de mundo [...] como na sua dimensão abstrata e simbólica [...] (BRASIL, 1997: 79).

Contudo, a fotografia, se analisada como indício interpretativo pelo docente, fornece trilhos, possíveis caminhos, para que o aluno possa compreender as proximidades e as diferenças culturais entre os grupos, além, da visualização de um período histórico. Talvez uma imagem não fale por mil palavras em todas as circunstâncias, porém, a união de ambas possibilita uma didática em sala de aula rica e plural.

Ainda que se interponham barreiras, ressalta-se a potencialidade da fotografia e sua pluralidade de funções; neste artigo mostrou-se sua viabilidade no auxílio ao processo de ensino, de modo particular, conforme requer os PCN's -pelo matiz da compreensão da diversidade- via imigração polonesa, porém, poder-se-ia abordar qualquer outra comunidade de imigrantes ou temáticas. Ou seja, esta atende a enredos plurais, cabendo ao professor orientar a ação pedagógica para um eficiente uso do campo visual.

\section{Considerações Finais}

As imagens podem não nos dizer tudo, entretanto, revelam aspectos, representações que podem nos informar etapas relevantes das tradições culturais, identitárias, etc. dos poloneses. De fato, a multiplicidade não é privilégio só das imagens, assim como nos evidenciou a Nova História Cultural e seus antecessores, entretanto, na presente pesquisa, o conjunto iconográfico recebe destaque, considerado de grande valia para o ensino de História.

O periódico enquanto fonte exercia na comunidade polonesa muito mais que um simples meio de informação, pois se configurava como um "guia" 
histórico, geográfico, social, etc. Desse modo, auxiliava os poloneses nas diversificadas esferas do cotidiano, atuando no imaginário destes, enfim, estimulando o sentimento de pertença.

Dessa forma, a noção de interculturalidade deve ser apropriada primeiramente pelo docente em sua práxis cotidiana, para, aí sim, alcançar o âmbito dos educandos. Há um árduo caminho a se traçar, que de fato já se inicia no cotidiano, mas que necessita de uma continuidade -tanto teórica, quanto prática.

A Gazeta Polaca, em suas páginas, seja na educação, religiosidade, atualidades, etc., estabelecia o elo identitário entre os imigrantes, aguçando neles, sentimentos plurais. Contudo, em algumas ocasiões parte-se do pressuposto de analisá-los como classe, grupo, etc., esquecendo-se em alguns momentos de seus sentimentos e as circunstâncias que os trouxeram para as Américas.Em síntese, a comunidade polonesa representada através do periódico torna-se uma dentre várias possibilidades para a inserção das imagens em âmbito escolar, dessa forma, canalizar e potencializar a atração exercida pela fotografia para as aulas de História.

\section{Bibliografia}

BACZKO, Bronislaw. Imaginação Social. IN: Enciclopédia Einaudi. Lisboa: Imprensa Nacional - Casa da Moeda, v.1, 1985.

BARTH, Fredrik. Grupos étnicos e suas fronteiras. IN: POUTIGNAT, Philippe; STREIFF-FENART, Jocelyne. Teorias da Etnicidade. São Paulo: Unesp, 1998.

BRASIL. Parâmetros curriculares nacionais. História. Secretaria de Educação Fundamental. Brasília: MEC/SEF, 1997.

BARTHES, Roland. Elementos de Semiologia. 2. ed. São Paulo: Cultrix, 1971.

BURKE, Peter. O que é história cultural? Rio de Janeiro: Zahar, 2001.

. Testemunha ocular: História e imagem. Bauru: EDUSC, 2004.

CAPRI, Elizabeth J. De católicos poloneses a ponta-grosensses católicos: a escola Sagrada Família: 1933 -1945. Curitiba: Dissertação de mestrado, UFPR, 2003.

CUCHE, Denys. A noção de cultura nas ciências sociais. Bauru: EDUSC, 1999.

CHARTIER, Roger. O mundo como representação. Estudos Avançados, São Paulo: v. 11, n. 5, 1991.

DIFEL, 1990.

A História Cultural: entre práticas e representações. São Paulo: 
DECOL, René. Uma História Oculta: a imigração dos países da Europa do Centro-leste para o $\quad$ Brasil. Disponível em $<$ http://www.abep.nepo.unicamp.br/docs/anais >.

DEMBICZ, Andrzej. Polono-Brasileiros. Curitiba: Braspol, n.1, 1998.

DOUSTDAR, Neda M. Imigração Polonesa: raízes de um preconceito. Curitiba: Dissertação de mestrado, UFPR, 1990.

ELIAS, Norbert. O processo civilizador: formação do Estado e civilização. Rio de Janeiro: Zahar, 1993.

GEERTZ, Clifford. A Interpretação das Culturas. Rio de Janeiro: Zahar, 1974.

HALL, Stuart. A identidade cultural na pós-modernidade. 3. ed. São Paulo: DP\&A, 1999.

HOBSBAWM, Eric. A Era dos Extremos: o breve século XX. São Paulo: Companhia das Letras, 1995.

JOLY, Martine. Introdução à análise da imagem. Campinas: Papirus, 1996.

KOSSOY, Boris. Fotografia \& História. 2 .ed. São Paulo: Ateliê Editorial, 2001.

LE GOFF, Jacques. A história nova. São Paulo: Martins Fontes, 1993.

MAUAD, Ana M. Através da Imagem: fotografia, história e interfaces. O Tempo, Rio de Janeiro, v.1, n 2, 1996.

LOPES, Alice Ribeiro C. Conhecimento Escolar: ciência e cotidiano. Rio de Janeiro: UERJ, 1999.

NAPOLITANO, Marcos. A História depois do papel: as fontes audiovisuais. In: BACELLAR, Carlos (et all.). Fontes Históricas. São Paulo: Contexto, 2005.

PESAVENTO, Sandra J. O imaginário da cidade. 2. ed. Porto Alegre: UFRGS, 2002.

Nova Escola: edição especial. Para entender Parâmetros Curriculares Nacionais. São Paulo: Abril, 2003.

POLLAK, Michael. Memória e identidade social. Estudos Históricos, Rio de janeiro, v.5, n.10, 1992.

v.2, n.3, 1989 .

Memória, Esquecimento, Silêncio. Estudos Históricos, Rio de Janeiro,

RÜSEN, Jörn. Razão Histórica. Teoria da História: os fundamentos da ciência histórica. Brasília: UNB, 2001.

SALLES, Iraci G. Trabalho, progresso e a sociedade civilizada. São Paulo: INL, 1986.

SANT'ANNA, Denise B de. Propaganda e História: antigos problemas, novas questões. Projeto História 14: Revista do Programa de Estudos Pós-Graduados em História e do Departamento de História da PUC-SP. São Paulo: PUC, 1981.

SANTOS, Rose S. dos. Integração de famílias imigrantes polonesas no município de Mallet-Paraná (1884-2005). Ponta Grossa: Monografia de conclusão da graduação, UEPG2005.

STAWINSKI, Alberto V. Primórdios da Imigração Polonesa no Rio Grande do Sul (1875-1975). Caxias do Sul: UCS, 1976. 
SEVCENKO, Nicolau. O Prelúdio Republicano, Astúcias da Ordem e Ilusões do Progresso. In: SEVCENKO, Nicolau (org). História da vida privada no Brasil. São Paulo: Cia das Letras, v. 3, 1998.

SILVA, Henrique M. Alguns Apontamentos Sobre o Uso de Fotografias em Pesquisas Históricas. Revista de História Regional, Ponta Grossa, v. 5, n. 2, inverno, pp. 137-148, 2000.

VIEIRA, Fábia Magali S. A internet como meio eletrônico de comunicação. Disponível em : < http://www.connect.com>.

Colaboração recebida em 16/03/2009 e aprovada em 30/06/2009. 